\title{
Experiência da família ao conviver com seQuelas decorrentes da prematuridade do filho
}

\author{
Family experience of dealing with seQuels of the prematurity of a child \\ Experiencia de la familia ao convivir con sequelas decorrentes de la prematuridad del hijo
}

\author{
Débora Cristina Arruda', Sonia Silva Marcon" \\ 'Universidade Estadual de Maringá. Hospital Universitário. Maringá, PR \\ "Universidade Estadual de Maringá. Departamento de Enfermagem. \\ Núcleo de Estudos, Pesquisa, Assistência e Apoio à Família. Maringá, PR
}

Submissão: 10/05/2009

Aprovação: 19/06/2010

\section{RESUMO}

O objetivo do estudo foi conhecer como famílias de crianças nascidas prematuras e com muito baixo peso tiveram a experiência de conviver com essa criança no decorrer dos primeiros anos de vida. Trata-se de um estudo Qualitativo, desenvolvido na cidade de Maringá, PR, Brasil, com a oito famílias de crianças nascidas no Hospital Universitário durante os anos de 1998 a 2000. Os dados foram coletados por meio de entrevistas abertas, realizadas no período de janeiro a junho de 2006 nos domicílios. As famílias revelaram a angústia e o sofrimento delas ao descobrirem aos poucos as limitações, diferenças e seeüelas decorrentes da prematuridade, bem como a longa trajetória em busca de uma melhor compreensão dessas consęuências surgidas no decorrer da infância.

Descritores: Família; Recém-nascido de baixo peso; Enfermagem pediátrica.

\section{ABSTRACT}

The objective of the study was to describe the experience of the family that lives with the sequels of prematurity in the first years of a child's life. That was Qualitative study developed in Maringá, PR, Brazil, with eight families of children born from 1998 to 2008 at a University Hospital. Data was collected through open interviews carried out at the home of the families in the period from January to June 2006 . The families of premature babies revealed the anguish and the suffering experienced when they found little by little, the limitations, differences and current seeuels of prematurity. They emphasized that this experience can be translated as a long path in search of a better understanding of the whole process.

Key words: Family; Infant, low birth weight; Pediatric nursing.

\section{RESUMEN}

El objetivo del estudio fue describir como es la experiencia de la familia de convivir con las secuelas de la prematuridad en los primeros años de vida del niño. Se trata de un estudio cualitativo Que fue desarrollado en la ciudad de Maringá, PR, Brasil, junto a ocho familias de niños nacidos en los años de 1998 a 2000. Los datos foueron recogidos por medio de entrevistas realizadas de enero a junio de 2006 en los domicilios de los respondentes. Las familias revelaron la angustia y el sufrimiento vivenciado al descubrir, a los pocos, las limitaciones, diferencias y secuelas decurrentes de la prematuridad y la larga trayectoria en busca de una mejor comprensión de las secuelas a lo largo de la infancia.

Descriptores: Familia; Recién nacido de bajo peso; Enfermería pediátrica. 


\section{INTRODUÇÃO}

Embora cada núcleo familial apresente suas próprias características na maneira de viver e ou conduzir o seu cotidiano e de interagir entre si, algumas Questões são comuns, como o sofrimento por causa de uma doença entre seus membros, de gravidez indesejada, de deficiências físicas e mentais, da morte entre outros. Assim, famílias Que têm um filho prematuro e com muito baixo peso (PMBP) - peso igual ou abaixo de 1500 gramas -, também experimentam situações em comum, embora possuam uma trajetória única de vida e importante de ser estudada(1).

O bebê prematuro com muito baixo peso - aquele Que nasce com menos de 34 semanas de gestação pode apresentar condições clínicas instáveis e predisposição a sérios e diferentes riscos relacionados à prematuridade. Interfere nessa condição, a época e o peso ao nascer, pois Quanto menores, maiores serão os riscos para problemas pulmonares, neuromotores, e entre outros ${ }^{(2)}$.

Os familiares dessas crianças, mais especificamente seus pais, são considerados grupos de risco. Além das mudança Que uma gestação normalmente provoca no núcleo familiar, estas são exacerbadas Quando a gestação tem complicações. Isso gera nos pais sentimentos de medo, perda e angústia. Além de já estarem debilitados com o sofrimento advindo das complicações da gravidez enfrentam, após o nascimento, a situação crítica de saúde do filho e a consequente necessidade de internação na Unidade de Terapia Intensiva Neonatal (UTIN), geralmente, por longos períodos ${ }^{(1)}$.

Com a internação do bebe na UTIN, os pais dão início a uma trajetória marcada por momentos dolorosos e estressantes e também pela separação do filho do núcleo familiar. O mundo do hospital e em particular o das UTIs é diferente e cheio de aparatos tecnológicos. Nesse ambiente, os pais passam a conviver inicialmente com a ansiedade pela estabilização do Quadro clínico, com o ganho e manutenção do peso e, por fim, com o período Que antecede a alta hospitalar. Na maioria das vezes, em função das inúmeras alterações em seu cotidiano, as famílias tendem a perceber essa trajetória como longa, mesmo Quando não o é de fato.

Isso pode comprometer o estabelecimento de vínculo paisfilhos $^{(3)}$, de tal forma Que a auto- confiança dos pais pode ficar abalada e, por conseguinte, interferir na capacidade de eles criarem o filho. Para complicar ainda mais, os profissionais permanecem muito tempo envolvidos com a assistência ao PMBP. Na maioria das vezes, não percebem Que o cuidado prestado não inclui a família e nem é desenvolvido com o intuito de promover e estimular o vínculo famíliar com a criança, bem como de estabelecer um acompanhamento Que represente apoio efetivo para os pais ${ }^{(4)}$. Embora a alta hospitalar seja desejada, no domicílio, os pais tendem a apresentar inúmeras dúvidas e a sentirem-se inseguros até mesmo em relação a alguns cuidados cotidianos ${ }^{(5)}$.

Apesar do risco de morte, a sobrevida dos recém-nascidos prematuros aumentou significativamente a partir da década de 1970, em decorrência do aprimoramento tecnológico das UTIs neonatais e da existência de profissionais capacitados para a intervenção e a condução adeQuada do processo de cuidar em neonatologia ${ }^{(2)}$.

Não obstante, uma preocupação dos profissionais da área de neonatologia e da Qual compartilhamos é a Qualidade de vida futura dos PMBP, Que pode estar comprometida por causa das seQuelas físicas e mentais muitas vezes irreparáveis ${ }^{(1,5)}$. Dessa forma, os profissionais precisam atentar para o fato de Que ter alta da UTIN não significa Que a família esteja pronta para cuidar do filho. Ela necessita de apoio para enfrentar as possíveis intercorrências durante o crescimento e desenvolvimento da criança $^{(1)}$.

Cabe considerar Que as famílias terão maior possibilidade de sucesso nessa empreitada se puderem contar com o apoio de profissionais, pois Quando orientada e sensibilizada, ela desempenha papel importante na promoção da saúde de seus membros. Esse apoio deve se fazer presente em todos os momentos: durante a internação, por ocasião da alta hospitalar e durante o acompanhamento ambulatorial, principalmente nos primeiros anos de vida, o Que ainda no Brasil se caminha a passos lentos ${ }^{(6-7)}$.

Este fato por si só já constituiria um indicativo da necessidade de acompanhamento dessas famílias em longo prazo, com o intuito de compreender melhor suas necessidades, subsidiar profissionais e políticas públicas, no apoio e na intervenção junto delas. Diante do exposto, o objetivo do presente estudo foi compreender como é a experiência da família de conviver com as sequelas da prematuridade nos primeiros anos de vida da criança.

\section{MÉTODO}

Trata-se de um estudo Qualitativo o eual adotou como linha metodológica uma associação entre os princípios da etnografia e da história de vida. Em suas experiências e sentimentos, as pessoas Que compartilham um histórico culturalmente semelhante, como o nascimento de um filho prematuro, caracterizam-se como grupos culturais Que tiveram experiências comuns ao conviverem com esse filho nos primeiros anos de vida. Com esta associação, valorizamos e reconhecemos a relação entre a vida individual e a social, assim como a necessidade de conhecer o fenômeno em estudo, pautado na visão de mundo, crenças, valores, saberes e práticas de Quem o experimenta ${ }^{(8)}$.

O estudo foi desenvolvido no município de Maringá-PR, com oito famílias de crianças residentes no município, nascidas PMBP e Que estiveram internadas na UTIN do Hospital Universitário de Maringá. Ele é uma instituição de referência para os 115 municípios da macrorregião noroeste do Paraná, na área de neonatologia.

Optou-se por estudar as famílias de crianças Que passaram pelo serviço em seus três primeiros anos de funcionamento (1998 a 2000), com os filhos em idade de cinco a sete anos, por entender Que elas já teriam acumulado experiências importantes na trajetória de vida relacionada ao cuidado e ao acompanhamento do crescimento e desenvolvimento do filho. Elas foram selecionadas a partir do livroregistro da UTIN. Neste período, estiveram internadas na UTIN 116 crianças PMBP. Destas, 35 evoluíram para óbito. Das 81 Que receberam alta, 36 residiam no município de Maringá e tinham registro completo de endereço residencial e telefone. Mas, só II foram localizadas e três delas se recusaram a participar da peseuisa.

Os dados foram coletados no período de janeiro a junho de 2006, por meio de consulta documental e entrevistas abertas. Os prontuários foram consultados para complementar e esclarecer informações relacionadas aos diagnósticos médicos (na hospitalização e acompanhamento ambulatorial), tempo de hospitalização, idade gestacional e peso ao nascer. As entrevistas foram previamente agendadas, realizadas no domicílio e gravadas 
após consentimento. Elas tiveram uma duração média de duas horas e meia e foram realizadas, considerando-se a seguinte Questão norteadora: Como foi para família criar este filho? As mães foram as informantes principais mas, em três famílias tios e avós maternos participaram efetivamente como ouvintes e depoentes.

Para cada uma das crianças foi estruturado uma espécie de "dossiê", composto de: dados de identificação, notas de campo e dados de entrevista e os obtidos do prontuário. As informações foram submetidos a um processo de análise de conteúdo ${ }^{(8)}$. Para tanto, inicialmente, as entrevistas foram transcritas na íntegra, e em seguida, submetidas a um processo exaustivo de leitura. As experiências das famílias foram agrupadas em ordem cronológica modo a permitir a identificação dos aspectos semelhantes e dos específicos experimentados por cada uma das famílias.

O desenvolvimento do estudo obedeceu aos preceitos éticos disciplinados pela Resolução 196/96 do Conselho Nacional de Saúde e o projeto foi aprovado pelo Comitê de Ética em Pesquisa da Universidade Estadual de Maringá (Parecer 382/2005). Todas as participantes assinaram o Termo de Consentimento Livre e Esclarecido em duas vias. Na apresentação dos resultados, os discursos dos sujeitos estão identificados com a posição dos entrevistados na família (mãe, avós, tios e outros), seguido de um nome fictício, retirado das personagens dos desenhos animados.

\section{RESULTADOS}

\section{Conhecendo algumas características das crianças e suas mães}

As mães das crianças em estudo (duas meninas e seis meninos), na época do parto, tinham idade Que variou de 16 a 34 anos e escolaridade média de oito anos completos. Cinco delas eram casadas. Apenas duas haviam planejado a gravidez. Por ocasião do estudo, três não exerciam atividades fora do lar (mães de Moranguinho, Limãozinho e Homem-Elástico) e duas trabalhavam em empresa familiar (mães de Faísca e Jimmy Nêutron). Das outras três, uma era diarista (mãe de Flecha), outra professora (mãe de He Man) e a terceira trabalhava no serviço de apoio de um hospital (mãe de Pão-de-Mel). A idade gestacional variou de 26 a 33 semanas, e o peso de nascimento, de 645 a 1445 gramas. Vale ressaltar Que seis crianças nasceram com 26 a 29 semanas de gestação e foram consideradas prematuros extremos, pois tinham peso inferior a 1000 gramas.

No Quadro 1, são apresentadas algumas características relacionadas ao nascimento, crescimento e desenvolvimento das crianças e nele se observa, por exemplo, Que o tempo de permanência na UTIN variou de 15 a 120 dias (média de 68 dias). As crianças nascidas com mais de 1000g (Pão-de-Mel e Jimmy Nêutron) são as Que apresentaram um desenvolvimento neuromotor mais próximo da normalidade e permaneceram menos tempo na UTIN.

\section{A família identificando diferenças no crescimento e desenvolvimento do filho PMBP}

A identificação de "diferenças" no desenvolvimento infantil do PMBP foi uma das representações encontradas em todos os discursos, e contemplou a percepção construída pela família no convívio com o filho após a alta hospitalar. Os relatos permitiram perceber Que nos casos de Pão-de-Mel e Jimmy Nêutron, Que nasceram com mais de $1000 \mathrm{~g}$, as diferenças foram percebidas de forma mais acentuada só nos primeiros meses de vida e estavam mais relacionadas à aparência física:

...todo mundo Queria ver, porque ele era muito pequeno (mãe de Jimmy Nêutron)

Eu peguei uma boneca pequena e coloquei do lado dela...ela cabia dentro da cama da boneca, tirei umas fotos. Você vê a foto hoje e fica abismada. A tia do meu marido chegou a dizer Que ela era parecida com lagartixa, eu fiquei muito triste... (mãe de Pão-de-Mel)

Essas diferenças, no entanto, segundo elas, foram minimizadas e, para algumas, crianças até desapareceram no decorrer do crescimento:

Aí, depois dos dois anos, ele pegou mais saúde... ninguém fala Que nasceu prematuro. (mãe de Jimmy Nêutron)

Nos demais casos, Quando as crianças foram para casa, as famílias já haviam se acostumado com a aparência física. As diferenças, embora percebidas também nos primeiros meses de vida, eram mais relacionadas com a maneira de a criança se comportar. Apresentavam muita irritabilidade, alteração na postura, no sono, entre outros, e tornaram-se mais evidentes Quando os pais comparavam o seu desenvolvimento com o de outros filhos ou de crianças da mesma idade.

Os discursos são reveladores do Quanto algumas famílias estavam desinformadas em relação às possibilidade de complicações decorrentes da prematuridade.

Eu não sabia Que ele poderia ter convulsão. Ele começou a babar, a repuxar os dedinhos da mão, vomitou, virou o olho e tudo mais... (mãe de Limãozinho)

Contudo, ao mesmo tempo em que pudemos inferir Que estas famílias não foram devidamente alertadas sobre as possibilidades de sequelas e ou complicações. E preciso reconhecer que algumas famílias muitas vezes não aceitam os diagnósticos informados e por essa razão os nega ou então não procuram conhecer mais sobre eles. Isto constitui uma das formas de enfrentamento encontradas pelas famílias para não sofrerem por antecipação. Por exemplo, Faísca recebeu alta da UTIN com indicação de uso de anticonvulsivante, mas esta terapêutica não foi seguida, pois a família, por interferência da avó materna, não se convenceu Quanto à necessidade e à importância do medicamento e acreditava Que a criança não necessitava dele:

...um dia, ele passou super mal, no outro dia como não melhorava, fui no médico e ela falou Que era convulsão, eu nunca tinha visto ele assim ... mas uma coisa é Que minha mãe não deixou dar remédio porQue ela acreditava muito em Deus, aí não sei se foi por isso... (mãe de Faísca)

Eu só fui descobrir a realidade, Quando eu saí e fui atrás do diagnóstico da minha filha. Foi uma coisa Que marcou muito, magoou muito. Se eu estou aqui é porque eu corri atrás... (mãe de Moranguinho) 


\begin{tabular}{|c|c|c|}
\hline $\begin{array}{l}\text { Criança } \\
\text { (idade atual e peso ao } \\
\text { nascer) }\end{array}$ & Hospitalização & Aspectos relevantes do desenvolvimento \\
\hline $\begin{array}{l}\text { Pão-de-Mel } \\
7 \text { anos } \\
\text { PN }-1345 \text { g }\end{array}$ & $\begin{array}{l}37 \text { dias no hospital } \\
15 \text { dias na UTIN }\end{array}$ & $\begin{array}{l}\text { Durante a infância apresentou doenças comuns, com desenvolvimento e crescimento adeQuados } \\
\text { para a idade. Executa tarefas próprias para a idade e freQuenta a primeira série com bom } \\
\text { desempenho. }\end{array}$ \\
\hline $\begin{array}{l}\text { Jimmy Nêutron } \\
6 \text { anos } \\
\text { PN }-1445 g\end{array}$ & $\begin{array}{l}35 \text { dias no hospital } \\
22 \text { dias na UTI }\end{array}$ & $\begin{array}{l}\text { Necessitou de acompanhamento pulmonar até os três anos de idade. Frequenta a pré-escola com } \\
\text { bom desempenho. Apresenta déficit visual (astigmatismo). }\end{array}$ \\
\hline $\begin{array}{l}\text { Moranguinho } \\
\text { Sete anos } \\
\text { PN }-795 \mathrm{~g}\end{array}$ & $\begin{array}{l}105 \text { dias no hospital } \\
90 \text { dias na UTIN }\end{array}$ & $\begin{array}{l}\text { Gemelar. Apresentou doença pulmonar da membrana hialina grau 4, anóxia neonatal grave, entre } \\
\text { outros. Tem retinopatia, microcefalia, tetraplegia espática, neuropatia crônica e digenesia do corpo } \\
\text { caloso. É totalmente dependente e desde os oito meses freQuenta escola especial de reabilitação. }\end{array}$ \\
\hline $\begin{array}{l}\text { Faísca } \\
5 \text { anos } \\
\text { PN }-900 \mathrm{~g}\end{array}$ & $\begin{array}{l}104 \text { dias no hospital } \\
90 \text { dias na UTIN }\end{array}$ & $\begin{array}{l}\text { Apresentou duas paradas cárdiorrespiratórias. Na alta hospitalar foi orientado uso de } \\
\text { anticonvulsivante, mas a família não seguiu. Aguarda cirurgia de fimose e hidrocele à esouerda aos } \\
\text { sete anos. Até os dois anos, teve várias internações por broncopneumonias e infecção urinária. } \\
\text { Andou com um ano e sete meses. Usa óculos com grau elevado desde os dois anos. Freeuenta a } \\
\text { pré-escola, é participativo e sociável. Não apresenta limitações fisicas e tem bom desempenho } \\
\text { escolar. }\end{array}$ \\
\hline $\begin{array}{l}\text { Homem Elástico } \\
7 \text { anos } \\
\text { PN - } 825 \mathrm{~g}\end{array}$ & $\begin{array}{l}06 \text { meses no hospital } \\
04 \text { meses na UTIN }\end{array}$ & $\begin{array}{l}\text { É portador de paralisia cerebral e retinopatia. Nos três primeiros anos foi internado várias vezes } \\
\text { por complicações pulmonares. Freeuenta escola de reabilitação desde os três anos de idade, mas } \\
\text { a família acredita Que este ingresso foi muito tardio, o Que atribui à falta de informação e às } \\
\text { hospitalizações muito freQuentes. }\end{array}$ \\
\hline $\begin{array}{l}\text { Limãozinho } \\
7 \text { anos } \\
\text { PN }-645 \mathrm{~g}\end{array}$ & $\begin{array}{l}03 \text { meses no hospital } \\
74 \text { dias na UTN }\end{array}$ & $\begin{array}{l}\text { Apresenta déficit motor e mental e hemiplegia à esQuerda. Andou aos Quatro anos. Apresenta } \\
\text { déficit de aprendizagem e é agressivo. Foi encaminhado para a APAE, mas a família não aceita. } \\
\text { Nos três primeiros anos, foi internado várias vezes por complicações pulmonares. }\end{array}$ \\
\hline $\begin{array}{l}\text { Flecha } \\
7 \text { anos } \\
\text { PN }-995 \mathrm{~g}\end{array}$ & $\begin{array}{l}04 \text { meses no Hospital } \\
03 \text { meses na UTIN }\end{array}$ & $\begin{array}{l}\text { Foi acompanhado por pouco tempo no ambulatório ( } 10 \text { meses). Nos dois primeiros anos, foi } \\
\text { intemado duas vezes por pneumonia. Andou com I ano e } 6 \text { meses. É agitado e muito ineuieto, } \\
\text { tem dificuldades de socialização. Esta aguardando tomografia de crânio para esclarecimento de } \\
\text { diagnóstico. }\end{array}$ \\
\hline $\begin{array}{l}\text { He Man } \\
6 \text { anos } \\
\text { PN }-910 g\end{array}$ & $\begin{array}{l}62 \text { dias no hospital } \\
47 \text { dias na UTIN }\end{array}$ & $\begin{array}{l}\text { Nos primeiros meses, houve suspeita de hidrocefalia e cardiopatia (sopro) Que não se } \\
\text { confirmaram. Andou com um ano e nove meses. Tem miopia importante - usa óculos. Apresenta } \\
\text { limitação física com déficit motor em pé eseuerdo, mas anda sem apoio. Faz fisioterapia. Executa a } \\
\text { maioria das atividades esperadas para a idade. Frequenta a pré-escola com bom desempenho. É } \\
\text { sociável e compreensivo. }\end{array}$ \\
\hline
\end{tabular}

\section{Quadro 1. Crianças nascidas PMBP internadas no Hospital Universitário de Maringá, no período de 1998 a 2000, segundo idade atual, peso ao nascer, tempo de internação no hospital e na UTIN e aspectos relevantes do desenvolvimento infantil.}

Este fato demonstra a importância de os profissionais de saúde considerarem os aspectos culturais e religiosos das famílias em seus planos de cuidado, oferecendo subsídios, durante todo o período de internação, para Que elas possam compreender a importância de determinadas condutas a curto, médio e longo prazos. Se as famílias não compreendem essa importância, provavelmente vão fazer valer sua percepção. Ademais, o fato de a família decidir não oferecer o medicamento ao filho demonstra o Quanto ela necessitava de apoio e orientação, pois as convulsões no período neonatal constituem manifestação clínica de uma grave doença de base, Que pode produzir lesão cerebral irreversível ${ }^{(1,3,9)}$.

É importante ressaltar Que as alterações no comportamento nem sempre são percebidas como prováveis manifestações patológicas. A possibilidade do choro, da irritabilidade e da agitação estarem associados à fome ou ao desconforto constitui causa de confusão para os pais. A persistência destes sintomas é Que vai despertá-los para um possível problema. A mãe de Moranguinho, por exemplo, relata Que a filha apresentava choro constante e irritabilidade intensa, o Que era muito diferente da forma como os outros três filhos haviam se comportado:

Porque ela não se comportava como uma criança da idade dela, porque além dela ser prematura, eu não sabia lidar com ela na parte do choro, da agitação. (mãe de Moranguinho)

\section{O impacto do diagnóstico de seQüelas e complicações nos primeiros anos de vida}

Esta categoria aborda as referências sobre sequelas que os PMBP apresentaram no decorrer da infância e o modos de enfrentamento experimentados pelas famílias. Em seus discursos, as famílias revelaram Que à medida Que, a criança crescia, elas começaram a perceber déficit em seu desenvolvimento, notado inicialmente pela demora em sentar, seguido do engatinhar, andar, falar e, posteriormente, no desempenho de habilidades motoras e mentais. Essas constatações 
eram norteadas principalmente pela comparação entre os irmãos. ...a primeira coisa que eu fui procurar realmente foi o que a Moranguinho tinha, porQue ela não se comportava como uma outra criança da idade dela, e eu já tinha três filhos, sabia Que não estava nada certo... A diferença era o choro, a irritação não eram normais. (mãe de Moranguinho)

O recém-nascido PMBP está sujeito a complicações cerebrais e é vulnerável a lesões isQuêmicas causadas por fluxo sanguíneo cerebral variável, Que pode ser tanto aumentado Quanto diminuído, decorrente da asfixia neonatal ${ }^{(1,5,9)}$. Além disso, existem alguns fatores de risco Que predispõe o PMBP à complicação neuromotoras. Como exemplos, destacam-se dois: os biológicos (Quanto menor a idade gestacional e o peso ao nascer, maiores serão os riscos) e os ambientais Que incluem deficiência nas condições socioeconômicas e culturais - uso de drogas na gestação, baixa renda, acompanhamento pré-natal inadequado, gravidez na adolescência, entre outros ${ }^{(4)}$

As seis crianças nascidas com menos de 1000 gramas (Moranguinho, Homem Elástico, Flecha e Limãozinho, Faísca e He Man) tiveram diagnóstico de anóxia neonatal e, em decorrência, apresentam danos físicos e mentais. Moranguinho e Homem-Elástico são os mais comprometidos e apresentam inclusive tetraplegia e microcefalia.

O oftalmo falou - Mãe, sua filha pode ter um problema neurológico. É microcefalia, a cabeça dela é pequena demais, vamos investigar... Daí que eu fui atrás do neuro pediatra em Maringá, aí veio o diagnóstico de hidrocefalia, problema motor... e voce vai ter Que colocar sua filha numa escola especial. (mãe de Moranguinho)

Lá em Curitiba, o médico disse que a retina dele não desenvolveu, devido ao uso de corticóide, oxigênio... e não poderia deixar ninguém mexer para não piorar mais ainda. Ainda disse assim, daqui uns dez anos, Quem sabe a medicina descubra alguma coisa nova que ele possa enxergar. Eu estava sozinha, voltei de lá super abalada. Depois, fui para São Paulo, e a doutora disse a mesma coisa... (Mãe de Homem-Elástico)

Apesar do importante papel do serviço de saúde na monitoração do desenvolvimento da criança, a família pode desempenhar um papel fundamental no diagnóstico precoce dos déficit dos PMBP. Isso é importante, pois, Quanto mais precocemente forem diagnosticadas, mais poderão ser minimizadas as deficiências físicos e mentais ${ }^{(5)}$. Não podemos nos esquecer Que a família, dada à proximidade e convivência diuturna, tem maiores condições de primeiramente perceber limitações e alterações. Mas, para isso, ela precisa estar devidamente esclarecida e preparada para aceitar a possibilidade de Que seu filho conviva com algum tipo de complicação:

Ele não andou Quando bebê, só se arrastava. (mãe de Flecha)

[... e eu levei no ortopedista porque ele demorou andar, com um ano e nove meses. (mãe de He Man)

É interessante observar Que as famílias, muitas vezes, são "culpabilizadas" por não terem procurado mais precocemente melhores recursos para o problema do filho:

O médico falou Que demorou muito para levar na escola especial, Que faltou estimulação, por isto ele usa a cadeira de rodas, não anda.... (mãe de Homem- Elástico)

Os relatos maternos acerca do desenvolvimento permitiram confirmar Que os PMBP nem sempre passam ou seguem as fases do rolar, sentar, engatinhar e andar. Ao abordar o desenvolvimento dos prematuros, alguns estudos ${ }^{(2,7,9)}$ apontam Que existe uma desordem no crescimento e desenvolvimento, comprometendo as habilidades motoras nos primeiros anos de vida. Limãozinho foi o Que mais demorou a andar:

Ele andou com Quatro anos, minha mãe nunca esqueceu, ela fala Que foi um milagre de Deus, nós achamos Que ele nunca ia conseguir .(mãe de Limãozinho)

Esta criança frequenta até hoje o ambulatório de ortopedia no HUM e é acompanhada pela fisioterapia desde um ano de idade. Ainda assim, mãe e avó se ressentem da falta de informações

Ele, às vezes, Quando corre ainda cai muito [...] mas quem diz Que Quer ajuda (avó de Limãozinho)

Foi difícil, a gente fica sem saber o Que fazer mais, ninguém fala porque ele ficou assim. (avó de Limãozinho)

Observa-se Que a família se ineuieta com o fato de estar pouco esclarecida a respeito dos problemas do filho. Alguns estudos têm demonstrado que as orientações da equipe de saúde foram isoladas, esporádicas, não-sistemáticas e nem individualizadas e, por esta razão, não foram capazes de acabar com a insegurança materna no cuidado ao filho prematuro ${ }^{(10)}$. Para isso, independente das orientações recebidas durante o período de hospitalização, seria necessário existir um serviço de atenção e suporte no domicílio, pois é neste ambiente e no cotidiano Que as dúvidas se fazem presentes.

Em alguns casos, no decorrer do crescimento da criança, ou seja, depois Que a criança alcança certa independência determinada pelo andar e o falar, parece eue as famílias diminuem a ansiedade relacionada com o desenvolvimento motor. Só passam a perceber Que existe algum déficit Quando a criança entra na fase/idade escolar. Isso porque, além de a criança manter contato mais frequente com outros da mesma faixa etária, essa é uma etapa cujas exigências de desenvolvimento são mais conhecidas pelos leigos. Isso permite Que eles percebam mais facilmente as alterações, como a deficiência na aprendizagem e na maturidade da criança, Que se mostra impróprio para a idade:

[... minha menina tem dois anos e é muito diferente. Não parece Que ele tem sete anos. Então eu acho assim, a professora fala Que ele Quer brincar embaixo da mesa, as atitudes dele é diferente, na frente das pessoas. As pessoas tratam diferente, ele se sente diferente... (mãe de Flecha)

De fato, as crianças nascidas PMBP apresentam maior dificuldade 
de concentração com baixo desempenho escolar. No entanto, embora a prematuridade constitua um fator de risco para as dificuldades de adaptação e desempenho escolar, não é um fator unicausal, já Que as condições econômicas, culturais e ambientais também são apontadas como contribuintes diretos para o desenvolvimento escolar dessas crianças $^{(7)}$. O desenvolvimento cognitivo de prematuros com muito baixo peso também é influenciado pela escolaridade e idade materna ${ }^{(6)}$. A escolaridade materna foi considerada o indicador mais adequado para medir indiretamente a estimulação cultural recebida em casa. E é mais efetiva Quando as mães têm nove ou mais anos de escolaridade. As mães adolescentes, por sua vez, podem comprometer a Qualidade do estimulo e acompanhamento dessas crianças, em decorrência da falta de comprometimento com horários e datas de agendamentos, privando a criança de receber tratamento adeeuado.

Em relação a esta variável cabe considerar Que, embora os índices de escolaridade materna tenha aumentando nos últimos anos, ainda se apresenta como um fator determinante da Qualidade do cuidado junto aos filhos com necessidades especiais. Isso porque normalmente os contatos com os profissionais de saúde são permeados por uso de termos técnicos, de forma Que as mães e os familiares, de forma geral, apresentam dificuldades em compreender a importância e os significados de estimular e encaminhar precocemente o filho PMBP para serviços e profissionais especializados.

A experiência da família de Flecha ilustra bem esse contexto. $\mathrm{O}$ histórico da hospitalização revelou Que, por diversas vezes, a criança esteve entre a vida e a morte, pois além do tempo demasiadamente longo na ventilação mecânica, a criança também foi submetida a dois procedimentos cirúrgicos de alta complexidade. Mas, a família, por meio de sua mãe, não parece reconhecer possíveis repercussões neurológicas Que o filho possa desenvolver ao longo da vida, e nem suspeitar que se trata de uma criança Que necessita de cuidados especiais. As atitudes e os comportamentos do filho levaram a mãe a perceber problemas relacionados com a adaptação e socialização da criança. Só por ocasião do ingresso na escola, é Que a criança recebeu um encaminhamento formal relacionado com a necessidade de procurar um serviço de neurologia. A mãe revelou, porém, estar com uma solicitação de tomografia de crânio há mais de um ano e Que ainda não tinha nem idéia de Quando o exame seria realizado.

Este fato, sem dúvida, revela a ineficiência do serviço público de saúde junto às crianças com necessidades especiais e Que deveriam ter prioridade no atendimento.

Durante a infância do filho PMBP, a família percebe o desenvolvimento comprometido e se depara muitas vezes com alterações Que são difícieis de serem explicadas e percebidas como anormais. Por essa razão, o parâmetro mais utilizado pelos pais no cotidiano, é mais uma vez a comparação, em especial, entre os próprios filhos. Isso lhes permite definir se o comportamento e as atitudes observadas estão alterados ou não.

O desenvolvimento dele aconteceu depois de um aninho. Eu vi pelo meu segundo filho, nasceu bem depois que ele mas sentou e falou bem rápido, e ele não, demorou muito... (mãe de HomemElástico).

No entanto, a comparação, poderia ser aprimorada e se tornar uma ferramenta mais segura e confiável, se as orientações dos profissionais de saúde Quanto às possíveis alterações Que o PMBP possa vir a apresentar fossem mais claras. As mães revelaram Que, diante da dificuldade em lidar com as diferenças e o comportamento "difícil" do filho, o que mais lhes marcou foi a falta de conhecimento e esclarecimentos sobre o Que seria ter um filho prematuro.

Nos primeiros meses depois que saiu da UTI, tudo já vinha aparecendo: era o choro demais, a irritação, não eram normais, como eu não tinha um conhecimento..., eu desconhecia e daí fui atrás de buscar esse conhecimento... orientação médica, pesquisa... como ela aprendeu a dar beijo? Começou a falar os fonemas? Tudo foi o estímulo Que a gente deu. (mãe de Moranguinho)

Observe-se Que, mesmo a mãe de Moranguinho que já tinha tido dois filhos e formação na área da saúde e permaneceu mais de três meses com a criança na UTIN, não conseguia distinguir e nem ter clareza Quanto às alterações percebidas no comportamento da filha, Quanto à sua normalidade ou não. Isso revela, mais uma vez, a importância do acompanhamento dessas famílias após a alta hospitalar. Aponta também Quão necessário é Que os profissionais das UTINs atentem para estes aspectos no momento de realizar orientações junto aos pais. É importante Que reconheçam Que estes, até em função de experimentarem vários sentimentos relacionados à hospitalização, nem sempre conseguem processar muitas informações ao mesmo tempo. É necessário fazer várias aproximações com os temas de maior interesse para a sustentação do cuidado no domicílio.

Por outro lado, ao manifestarem suas percepções de Que o filho apresentava atitudes inadequadas para a idade, as mães revelam Que as famílias do PMBP podem deparar-se com alterações de comportamento desde o nascimento e em diferentes momentos da vida da criança:

Ele sempre foi assim, desde bebê, a gente não conseguia controlar. (mãe de Flecha)

Os discursos revelaram também outros déficits, além do motor. Das oito crianças, seis (Moranguinho, Homem-Elástico, Limãozinho, Faísca, He Man e Jimmy Nêutron) são portadores de problema visual. Moranguinho e Homem-Elástico apresentam perda total da visão decorrente de retinopatia. As demais apresentam perda parcial, com necessidade rotineira de óculos de graus variados:

A primeira coisa que eu reparei aos dois anos foi que ele, tudo Que ia ver aproximava do olho, brinquedo[... era tudo de pertinho, daí veio o óculos, de 12 graus num olho e 13 no outro.Agora, (aos sete anos) é sete e oito, mas ainda é muito. (mãe de Limãozinho)

Descobrimos o problema dele porque um dia tava passando um avião e nós mostramos e ele não enxergava..., ai o médico lá no HU falou Que era problema no nervinho. (mãe de Faísca)

Levei no oftalmologista com menos de um ano, ele usa óculos desde bebê, cinco graus de miopia. (mãe de He Man)

A família de Moranguinho tomou conhecimento da retinopatia 
aos oito meses, mas a do Homem-Elástico só aos três anos. Justificam porQue até então estavam todos preocupados e envolvidos com as inúmeras internações decorrentes da insuficiência respiratória:

Aos três anos, eu soube o Que aconteceu foi Que a retina dele não desenvolveu, devido ao uso de corticóide, oxigênio e a gente não pode mexer. (mãe de Homem Elástico)

Nas crianças com maior comprometimento da função visual, a trajetória até o diagnóstico foi mais desgastante e doloroso:

Antes de um ano, ela foi encaminhada para um retinólogo. Passei por vários lugares até receber o diagnóstico da retinopatia. (mãe Moranguinho)

O fato de essa complicação estar associada à prematuridade $\mathrm{e}$ aos riscos Que essas crianças viveram ao nascer, desencadeia no âmbito familial sentimentos de perda. Perda do filho perfeito e esperado ou da parte comprometida de seu corpo. Vive-se aqui, o sentimento de luto, uma vez Que não só a morte significa perder ou separar-se daQuilo Que se ama, mas também a perda segmentar do corpo, nesse caso, a visão.

Algumas famílias também se depararam com a suspeita ou confirmação de déficit na acuidade auditiva. O diagnóstico tardio dessa complicação é revelador de Quanto os serviços de saúde são deficientes na assistência aos PMBP, pois o risco de um prematuro apresentar perda auditiva neurossensorial bilateral é de 6 a 12 vezes maior do Que em neonatos saudáveis ${ }^{(1)}$. Além disso, esta condição poderia ser diagnosticada precocemente por meio da aplicação de testes específicos em bebês de risco - aqueles que apresentaram anóxia neonatal, uso de medicamentos ototóxicos, peso ao nascer igual ou inferior a 1500 gramas, permanência em incubadoras por mais de sete dias e internação prolongada em UTIN ${ }^{(1)}$.

Esses testes, porém, apenas são utilizados como rotina em grandes centros o Que revela a deficiência na assistência:

O pessoal da escola, Quando iniciei (após os três anos) me disse que ele precisava de estimulação e também realizar o teste de audiometria... (mãe Homem-Elástico)

Dentre outras complicações percebidas e relatadas nos discursos, encontram-se as cardíacas e pulmonares, Que, de fato, são muito frequentes em crianças nascidas $\mathrm{PMBP}^{(5)}$. Entre as crianças do estudo, três delas necessitaram de investigação ou acompanhamento cardiológico nos dois primeiros anos de vida:

\section{[...] o cardiologista suspeitava de sopro. (mãe de Limãozinho)}

Fiz três ecocardiograma mas não deu nada. (mãe de He Man)

Ele ficou no ambulatório da cardio até os dois anos, depois não deu mais nada. (mãe de Faísca)

As complicações pulmonares, por sua vez, mostraram-se mais presentes e mais graves, revelando Que, na concepção das famílias, essas complicações são mais difícieis de se resolverem:

Ela fez muito tempo fisioterapia respiratória (mãe de
Moranguinho); Até os três anos, ele era no oxigênio direto [...] (mãe de Homem-Elástico)

Ele teve muita penumonia até os dois anos, era direto no hospital (mãe de Flecha); Ele fazia fisioterapia respiratória e motora, porque ele tinha displasia. (mãe de He Man)

A displasia broncopulmonar foi um dos diagnósticos encontrados na maioria dos registros dos prontuários das crianças durante o tempo de internação na UTIN. Essa patologia é crônica e interfere decisivamente no crescimento e desenvolvimento da criança ${ }^{(2,5)}$.

As doenças hemorrágicas decorrentes da prematuridade, mais frequentemente referidas na literatura, são a paralisia cerebral, convulsões e hidrocefalia ${ }^{(1,9,12)}$ e todas elas foram identificadas nos relatos das mães:

Aí, veio o diagnóstico de hidrocefalia e o problema motor, a paralisia. (mãe de Moranguinho)

Na tomografia e ressonância magnética deu mancha no cérebro. Segundo o médico, essas manchas foram das paradas cardíacas Que ele teve na UTIN, pela falta de oxigênio. (mãe de Limãozinho)

Quando eu levei na pediatra, ela suspeitou de hidrocefalia devido o perímetro cefálico estar crescendo muito rápido. Daí, a neuro disse que não, Que o cérebro dele tinha sofrido muito, mas iria recuperar. (mãe de He Man)

Nestes relatos, dois aspectos merecem destaque: primeiro é que os pais sofrem com os defeitos físicos dos filhos, aqueles Que são aparentes, pois estes alteram sua forma e estrutura; mas sofrem também com a suspeita e a demora na confirmação de diagnósticos. Segundo, é que nem sempre as orientações fornecidas pelos profissionais são compreendidas pelas famílias. Interfere nesta compreensão, a forma como as orientações são feitas e os termos utilizados, de modo Que, as informações oferecidas não conseguem reduzir ou amenizar a ansiedade e nem suprir a necessidade de esclarecimento dos pais ${ }^{(13,14)}$. Pelo contrário, muitas vezes, contribui para aumentá-las.

Assim, os profissionais precisam compreender Que o preparo para a alta dessas crianças inicia-se já por ocasião de sua admissão na UTIN ${ }^{(15)}$. Nesse processo, é imprescindível identificar a percepção Que a família tem da situação, é preciso usar uma linguagem Que seja passível de compreensão pelos pais e Que as informações oferecidas atendam às suas reais necessidades. Além disso, é importante estender a assistência para além dos muros hospitalares, por meio de seguimento ambulatorial do crescimento e desenvolvimento dessas crianças e, se possível, realizar também acompanhamento do cuidado prestado no domicílio ${ }^{(16)}$.

As famílias de PMBP necessitam de ajuda e amparo por parte dos serviços de saúde ${ }^{(17)}$. O acompanhamento no domicílio representa um apoio protetor, pois possibilita Que elas sejam fortalecidas no desenvolvimento de cuidados e ações voltadas à promoção da saúde dessas crianças ao longo da vida. Sobretudo, por permitir detectar precocemente anormalidades no desenvolvimento infantil, e assim auxiliar a família na procura e no 
direcionamento do tratamento dentro dos serviços de saúde.

\section{CONSIDERAÇÕES FINAIS}

As famílias do estudo revelaram Que conviver com um filho nascido PMBP não é uma tarefa fácil, pois, desde o nascimento, enfrentam momentos de luta e busca pela compreensão do diagnóstico e tratamento dos problemas de saúde da criança. Ressalta-se Que todas as famílias revelaram ter sofrido muito ao se depararem, de forma inesperada, com sequelas e complicações. Muitos dos problemas de saúde constatados, como o déficit motor, deficiência de aprendizagem e visual, retinopatia, agitação, paralisia cerebral, tetraplegia espática, entre outros, foram percebidos e diagnosticados aos poucos, ou seja, ao longo dos anos e a partir da convivência e dos acompanhamentos médicos hospitalares.

Assim, além do sofrimento, algumas famílias demonstraram também dificuldade de compreender e aceitar as deficiências encontradas, mobilizar-se adeQuadamente na utilização e na busca de recursos formais e informais relacionados com a assistência às crianças com necessidades especiais. Neste contexto, o ingresso na escola também se mostrou ser uma fase na vida da criança Que foi vivenciada com angústia pela família, em decorrência tanto dos déficit de aprendizagem como daqueles relacionados com a adaptabilidade e a socialização dela.

Isso constitui um indicativo da necessidade de crianças nascidas PMBP serem acompanhadas longitudinalmente por equipe multidisciplinar. Destarte, suas famílias também necessitam de apoio e incentivo para cuidá-los com Qualidade. Para tanto, elas precisam ser informadas sobre possíveis complicações decorrentes da prematuridade. No entanto, segundo as informantes, os profissionais de saúde, via de regra, não informaram e nem anteciparam possíveis complicações Que as crianças pudessem vir a apresentar em sua trajetória de vida.

Acreditamos Que os profissionais, além de considerarem a interferência de aspectos socioeconômicos e culturais nas condições de vida da criança nascida PMBP, precisam reconhecer seu papel relevante com a essas famílias. Os serviços de saúde ainda não estão devidamente preparados para atenderem esses clientes e Que os recursos disponíveis na rede pública são insuficientes para garantirem o cuidado necessário a essas crianças, Que podem apresentar uma gama de problemas e necessidades decorrentes da prematuridade extrema.

\section{REFERÊNCIAS}

1. Tronchin DMR, Tsunechiro MA. A experiência de tornarem-se pais de prematuros: enfoque etnográfico. Rev Bras Enferm 2005; 58(1): 49-54.

2. Segre CAM. Rn pré-termo. In: Segre CAM. Perinatologia: fundamentos e prática. São Paulo: Savier; 2002. 96-1 14.

3. Scochi CGS, Kokuday MLP, Riul MJS, Rossanez LSS, Fonseca LM, Leite AM. Incentivando o vínculo mãe-filho em situação de prematuridade: as intervenções de enfermagem no Hospital das Clínicas de Ribeirão Preto. Rev Latino-am Enfermagem 2003; 11 (4): 539-43.

4. Centa ML, Moreira EC, Godoy MN, Pinto IR. Experiências vividas pelas famílias de crianças hospitalizadas em uma unidade de terapia intensiva neonatal. Texto Contexto Enferm 2004; 13 (3): 444-51.

5. Rugolo LMSS. Crescimento e desenvolvimento a longo prazo do prematuro extremo. I Pediatr 2005; 81 (supl 1): 10 I-10.

6. Méio MDBB, Lopes CS, Morsch DS. Fatores prognósticos para o desenvolvimento cognitivo de prematuros com muito baixo peso. Rev Saúde Pública 2003; 37(3): 3 I I-8.

7. Gaíva MAM. A vida escolar de crianças nascidas prematuras. Colet Enfermagem 2004; 3(1):9-13.

8. Minayo MCS. O desafio do conhecimento-peseuisa Qualitativa em saúde. 10ª ed. São Paulo: Hucitec; 2007.

9. Pasoval JM, Koenigsberger MB. Paralisis cerebral: factores de riesco pré natales. Rev Neurol 2003; 37(3): 275-80.

10. Soares, D. C. Vivenciando o ser prematuro extremo e sua família

no contexto hospitalar e domiciliar. Rev Eletron Enferm 2008: 10 (3): 864-5.

1 1. Ichisato SMT. Ruído em Unidade de Terapia Intensiva Neonatal de um hospital universitário de Ribeirão Preto SP. [tese]. São Paulo: Escola de Enfermagem de Ribeirão Preto, Universidade de São Paulo; 2004.

12. Pridham KA, Krolikowski MM, Limbo RK, Paradowski J, Rudd $\mathrm{N}$, Meurer IR, et al. Guiding mothers' management of health problems of very low birth-weight infants. Public Health Nurs 2006; 23(3): 205-15.

13. Starke M, Moller A. Parents' needs for knowledge concerning the medical diagnosis of their children. Child Health Care 2002; 6(4): $245-7$

14. Hopia H, Paavilainen E, Astedt-Kurki P. Promoting health for families of children with chronic conditions. J Adv Nurs 2004; 48(6): 575-83.

15. Tamez RN, Silva MPJ. Enfermagem na UTI neonatal- assistência ao RN de alto risco, Rio de Janeiro: Guanabara-Koogan; 2002.

16. Viera CS, Mello DF, Oliveira BRG. The follow-up of the family of the premature and low-birth-weight infant discharged from the NICU: a literature review Online Brazilian Journal of Nursing [serial on the Internet]. 2008 October 13; [cited 2009 May 2010]; 7(3). Available from: http://www.uff.br/objnursing/ index.php/nursing/article/view/1724

17. Simioni AS, Gelb LTC. Percepção materna Quanto ao apoio social recebido no cuidado às crianças preamturas no domicílio. Rev Bras Enferm 2008; 61(5): 645-5I. 